\title{
Shiva's dance of the relational interface
}

\author{
Karamjit S. Gill
}

Published online: 13 January 2015

(C) Springer-Verlag London 2015

In the midst of the turbulence of digitally mediated world redefining our sensory experiences, whether in the form of artificial life, biological robotics, trans-humanism, virtual identity, we note a concern about the vulnerability of the self. As Greenfield (2009) notes that when this individual sense of self is threatened (e.g. electronic surveillance), our very worst fears are ignited, since there no longer exists a 'fire wall' of group identity, family or social identity, between the inner self and the outside world. Sennett (1998) in his book, The Corrosion of Character, draws our attention to the turbulence of fragmented self and notes that in the brave new economy, the fragmented or dislocated nature of self-experience moves to the fore, thereby setting the scenario for an emotionally adrift and vulnerable self, losing control of the purpose of life and feeling the loss of the sense of the self. (ibid:130). It is held that central to the turbulence of the self and society, is the dominance of technologic of seeing things in terms of the I-It relation, objects of calculation, moving away from the I-Thou framework of judgement. It is this shift from judgement to calculation (Weizenbaum 1976) which leads to perceiving human relations, may they be social, cultural, ethical, economic, governance, in terms of I-It relations. The summary on Martin Buber's I and Thou (SparkNotes Editors 2014) notes that Buber looks at modern society and finds: 'how it is entirely built up based on the mode of I-It. Politics, economics, public institutions, even much of personal life, are all fundamentally grounded in the fact that we view every other being as an It, rather than as a Thou. Modern man has come to feel alienated fundamentally because modern society is exclusively an It-world.

K. S. Gill ( $₫)$

University of Brighton, Brighton, UK

e-mail: kgillbton@yahoo.co.uk
Existential angst, worries of meaninglessness, and the sense of impending doom that most modern human beings feel at some point in their life (often in the dead of night, when they cannot sleep) are all the result of our strict reliance on experience to the exclusion of encounter'. Bloch (2010) and Scott (2002) give a deep insight into Buber's I-Thou and I-It relations, in which Buber sets out a philosophy of relating. The experiencing I in an I-It relation is an objective observer rather than an active participant in this mode of engaging the world. In the IThou relation, we are present with others; it is the presence of others which influences our own sense of presence (Gill 2015) and creates an environment for us to be active participants rather than just mere objective observers. In our multipolar world of reality (observed) and actuality (the world as it is), I-It and I-Thou relations, in many ways, intersect, overlap, converge and diverge, making us seek a balance between these relations in a way that valorises their purpose and impact. In this perspective, we may say that we are seeking a relational interface of balance in the sense of harmony, kyosei, Yin-Yang, Symiotics, Swikriti (Gill 2009). The Dancing Shiva or Nataraja (Ramachandran 2012) depicts the very spirit of balance of actuality and reality of our universe, and from our perspective, provides a holistic model for conceptualising, creating and building relational interfaces.

In viewing metaphysic as 'beyond' the physical, Rao (2014) gives an insight into the idea of subject (I, Thou) and object (It). In accepting, One-Godhead as the "ultimate', Monotheistic religions (e.g. Judaism, Christianity and Islam) accept duality of subject (the worshipper) and the Object (the Worshipped-the God). He further says that although Monism (Non-dualism) appears to deny Godhead, it accepts God as having an ontological status at least ad hoc. What is of interest to us in the case of the 
Ultimate as the Thou and It (object) is the interface between the I (the worshipper)-Thou (the Ultimate) and IIt (object of worship). If beyond the physical, I and Thou become the same or merge into one, then what is the meaning of the mediating interface? How would an understanding of the idea of beyond the physical help us in the design of interface between the self and the other where other is either Thou (in the sense a person, you) or It? This then raises the issue as to the purpose of the interface, whether it is relational (e.g. purposive) or transactional (e.g. causal) (Rosenbrock 1990). In other words, whether it is about mediating reality as it is observed (factual), or it is about mediation of actuality (the world as it is). We perceive nature not as it exists in itself, but rather our perception of nature and its objects is necessarily determined by the structure of our minds. Hence, the totality of human beings' perceptions is only objective to the extent that we determine reality through the same operations of mind. In other words, reality is as nature is experienced, and ultimate reality lies beyond the realm of possible experience. Rao (op.cit.) notes that ultimate reality (Advaita) is not an object to be worshipped, rather it is the Subject itself when the veil of ignorance (avidy $\bar{a}$ ) is removed. So is the case with Buddhism since the Ultimate is an Absolute Nothingness - neither the worshipped nor the worshipper exists at that stage.

We note that Just as an object, when viewed from an extreme distance away from it, is non-existent for the viewer, we have in Buddhism, the 'view' of the complete Universe that never obtains, because the subject who is dependent on the material goes on diminishing in his own constitution, and when the matter completely vanishes, the subject also vanishes into thin air, making it impossible to view the resulting 'Nothingness'. This Buddhist view of the universe helps us to view the distancing self in the cyber sphere, where the self (I), when replicated in the cyber space, slowly and slowly moves away from its original contact and constraints and takes on a life as a virtual self, as if the 'I' has merged into the object beyond or beyond Thou. This non-ontological existence of the self in the cyber space poses a challenge as how to identify and differentiate the self from the 'virtual self'.

We further get a glimpse of the I-Thou relation as an outside-inside relation, when the worshipper enters from outside into physical space of worship, represented by the physical architecture of various religions (e.g. Church, mosque, Temple), and re-enters back from inside to the outside. The main entrance or multiple entrances of the architecture enable the worshipper (I) to enter from outside to the inside where the Ultimate (Thou) is believed to be represented or to reside or to be found. For example, in the case of Kaaba, Rao (ibid.) sheds light on the outside-inside relation: '...for those who enter the Kaaba, there is
Zamzam, the Ultimate Water, symbolising 'concretely' the 'Conscious-space' inside the Kaaba,....the Kaaba and Zamzam are identical entities, where Zamzam symbolically represents the total conscious space; and the Kaaba permits entry to pilgrims, which indicates the identity between pilgrim and the Ultimate. This identity is a Subjectual experience of the highest order.' The worshipper enters from outside Kaaba to inside architecture, Zamzam, through the entrance of Kaaba and seeks oneness with the Ultimate. The architecture of the Golden Temple (Sikh shrine at Amritsar) complex provides yet another insight into outside-inside relation; the worshipper enters the temple complex through any of the four entrances, then enters the Golden Temple, and can come outside through any of the four entrances. The representation of religions through their architectures illustrates the diversity of paths the worshipper follows or enters to seek oneness or solace with the Ultimate. It is interesting to note that in Buddhism, a mandala (Mandalas 2004) is a sacred geometric figure, a symbolic architecture, that represents the universe. By mentally entering a mandala and proceeding to its centre, a person is symbolically guided through the cosmos to the essence of reality. Mandalas are constructed from the centre outward, beginning with a dot in the centre. Outside the square temple are several concentric circles. The outermost circle is usually decorated with stylised scrollwork resembling a ring of fire. This ring of fire symbolises the process of transformation humans must undergo before being able to enter the sacred territory within. It both bars the uninitiated and symbolises the burning of ignorance. The innermost ring is made of lotus leaves, signifying religious rebirth. The square structure in the middle of a mandala is a palace for the resident deities and a temple containing the essence of the Buddha. The square temple's four elaborate gates symbolise a variety of ideas, including four boundless thoughts of loving kindness, compassion, sympathy and equanimity, and four directions: south, north, east and west. In the centre of the mandala is an image of the chief deity, who is placed over the centre dot described above. Because it has no dimensions, the centre dot represents the seed or centre of the universe. It is interesting to note that in Buddhist Mandala, there is no outside-inside divide.

We note that a variation of the outside-inside relationship between the worshipper and the Ultimate is reflected in the architectural (geometric) representations of many religions, illustrating again the diversity of the fundamental concept of the cyclic (I-Thou-I) relation. From the perspective of conceptualising interface, what is of interest to us is the transition of the worshipper from the social environment (outside) to a spiritual environment (inside) and back to the social environment (outside) and what it implies for designing relational interfaces. We could argue 
that this outside-inside-outside transitional cycle enables the worshipper to gain spiritual knowledge and wisdom when inside and bring to bear this knowledge when reentering the outside. In a wider context, the lesson we can draw from the spiritual outside-inside relation which is of interest to us is that of its appropriation in cross-social, cross-cultural, cross-boundary, cross-ethnicity contexts.

This outside-inside-outside cyclic relationship thus provides a perspective of deigning an interface, which is much more than transactional; it is relational in a deep sense enabling, mediating and supporting the generation and regeneration of knowledge and wisdom. Such a perspective cultivates an interfacing environment, which is holistic, participative, reciprocal, reflective, and immersed into human values of trust, ethics, inhabiting the diversity of social and cultural contexts of the individual and of the collective. The concept of outside-inside is seen here in terms of symbiotic relation of trust of I and hospitality of Thou, and the extended concept of outside-inside-outside is seen in terms of reciprocity, reflection, transfer, and change. The metaphysical concept of 'beyond' is taken to mean extended space/environment (e.g. virtual space) for I-Thou and I-It interaction. These concepts, when appropriated in relational contexts, provide for a conceptual framework for relational interface design.

What is of interest to us is to seek a conceptual model/ framework which provides for the appropriation of these concepts for relational interfacing, balancing the impact of the turbulence of mediating technologies and their emancipatory purposes. Further, we seek in this conceptual model a vision of balance between the individual and collective, between I and Thou, between the asymmetry and symmetry, between the reality and actuality, and between the real (material) and the virtual (beyond). Shiva's dance, in the form the artist's vision of The Dancing Shiva, or Nataraja (Ramachandran 2012), depicts the cosmic dance of Shiva, who creates, sustains and destroys the Universe. For example, the centrifugal motions of Shiva's arms and legs flailing in different directions and the way the tresses flying of his head symbolise the agitation and frenzy of cosmos. Yet right in the midst of all this turbulence-this fitful of fever of life-is the calm spirit of Shiva, movement and energy on the one hand, and the eternal stability on the other. This sense of something eternal and stable (the Ultimate) is conveyed by Shiva's slightly bent leg, which gives him balance and poise even in the midst of his frenzy, and partly by his serene, tranquil expression, which conveys a sense of timeliness. Shiva's dance thus symbolises a balance between I-Thou and I-It relations, between Outside-Inside relations, between reality and actuality, and between rationality and spirituality, in a world of turbulence of relations. It is as if Shiva's dance mediates the turbulent relations of self and society back to the reality-actuality balance of our world. The outside-inside relation here symbolises a relational interface that is more than transactional interaction, communication, and exchange; it is about reflective exchange, change, and transition on the part of both the designer and the user. A relational interface in this perspective affects reflective dialogue, mediation, reciprocity, and mutuality. This mediated balance of I-Thou and I-It relations, and those of the outside-inside relations, is what I call Shiva's dance of relational interface. The diversity of issues and arguments presented in Part A of this volume makes us reflect on the nature of turbulences arising from the dominance of technologics while exploring the societal relevance of technological innovations.

Acknowledgments This editorial is inspired by Ramachandran's reflective depiction of Shiva's dance in his book, The Tell-Tale Brain, and Rao's paper on Metaphysic and Religion in this volume. An insight into Buber's I-Thou and I-It relations by Bloch, Spark Notes and Scott is very much appreciated.

\section{References}

Bloch P (2010) Martin Buber (1878-1965). http://blochhealing.co.uk/ philosophical-context-pt-1/4549042853. Accessed 14 December 2014

Gill KS (2009) Mind the cross-cultural gap. In: Gokah TK (ed) Contemporary Discourses on IE and C theory and practice. Nova Science Publishers Inc, New York

Gill SP (2015) Tacit engagement. Interaction beyond the transactional. Springer, London

Greenfield S (2009) ID: the quest for identity in the 21st century: the quest for meaning in the 21 st century, Sceptre

Mandalas: Sacred Art and Geometry (2004). http://www.religionfacts. com/buddhism/things/mandalas.htm. Accessed 1 January 2015

Ramachandran VS (2012) The tell-tale brain. Windmill Books, London

Rao VK (2014) On the metaphysical meaning of major religious symbols for a globalized world, AI\&Society, Online publication, Springer, November 2014

Rosenbrock H (1990) Machines with a Purpose. Oxford University Press, Oxford

Scott A (2002) Martin Buber's I and Thou (Ich und Du, 1923). http:// www.angelfire.com/md2/timewarp/buber.html. Accessed 14 December 2014

Sennett R (1998) The corrosion of character. Norton, New York

SparkNotes Editors (2014) "SparkNote on I and Thou." SparkNotes LLC. n.d. http://www.sparknotes.com/philosophy/iandthou/ summary.html. Accessed December 14, 2014

Weizenbaum J (1976) Computer power and human reason: from judgment to calculation. W. H. Freeman, An Francisco 